\title{
Role of ascorbic acid in dapsone induced methemoglobinemia
}

\author{
Kamal Kant Sahu, Ajay Kumar Mishra \\ Department of Internal Medicine, Saint Vincent Hospital, Worcester, MA, USA
}

\section{Dear Editor,}

We read with great pleasure the recent article published by Kang et al. ${ }^{1}$ titled "Therapeutic effect of ascorbic acid on dapsone-induced methemoglobinemia in rats." The authors have explicitly mentioned the experience of ascorbic acid in animal model. Dapsone is a commonly used drug, especially in many medical and dermatological conditions. We would like to share our previous experience with ascorbic acid in the management of methemoglobinemia, along with a brief review regarding the recent advancement done in the field of dapsone related methemoglobinemia. $^{2-5}$

Methemoglobinemia remains one of the most challenging yet rewarding entity if managed promptly. ${ }^{2-5}$ Awareness about this disease prevents unnecessary investigations and ensures timely management. ${ }^{6-8}$ As evident from our previously reported cases, use of ascorbic acid was rewarding and a life saver. ${ }^{2-5}$ The maximum cumulative dose used by us was $14 \mathrm{~g}$. Recently, Reeves et al. ${ }^{9}$ reported using ascorbic acid as high as $30 \mathrm{~g}$ in a case of rasburicase induced methemoglobinemia.

A high degree of suspicion (common clinical clue being saturation gap) is the initial telltale sign supported by clinical findings and ancillary labs in diagnosing methemoglobinemia. Senthilkumaran et al. ${ }^{6}$ explicitly mentioned about the additional bedside test that could be performed even at the remote health care centers with limited lab assistance. (1) Filter paper test: No change in chocolate brown color of blood drop placed on a white filter paper on exposing to atmospheric oxygen. (2) Cooking and cooling test: Change of color (from chocolate brown to pink) of clotted blood sample in a test tube upon placing in boiling water bath followed by cooling. (3) Methemoglobinemia color chart: Originally developed by Shihana et al. ${ }^{10}$ from Sri Lanka which not only helps in diagnosing the methemoglobinemia but also helps in estimating the percentage of methemoglobinemia in a semi-quantitative manner.

For readers, another point to note is that dapsone even in topical form can cause methemoglobinemia. This was first reported by Swartzentruber et al. ${ }^{7}$ in the annual meeting of the American College of Medical Toxicology, 2014 and later published in the New England Journal of Medicine as well. Interestingly following this report, Allergan, the maker of Aczone topical dapsone gel (inciting drug in this report) also commented that they did not experience any such topical route associated methemoglobinemia during the clinical trial phase. ${ }^{11}$ Though rare, knowledge of this side effect is important for both dermatologists and patients as the topical gel is one of the commonly used drugs for acne vulgaris.

We used ascorbic acid with 100\% response rate and mortality benefit without using methylene blue. In general, methylene blue is considered the antidote of choice with ascorbic acid being used as an alternative therapy. For internists, it is also important to keep in mind that meth-
Received: 3 October 2018

Revised: 19 November 2018

Accepted: 20 November 2018

Correspondence to: Kamal Kant Sahu Department of Internal Medicine, Saint Vincent Hospital, Suite 120 South, 123 Summer Street, Worcester, MA 01608, USA

E-mail: Kamalkant.Sahu@ sstvincenthospital.com

ORCID

http://orcid.org/0000-0002-0382-6882

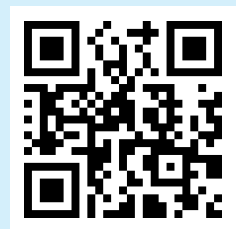

How to cite this article:

Sahu KK, Mishra AK. Role of ascorbic acid in dapsone induced methemoglobinemia. Clin Exp Emerg Med 2019;6(1):91-92.

This is an Open Access article distributed under the terms of the Creative Commons Attribution Non-Commercial License (http:// creativecommons.org/licenses/by-nc/4.0/). 
ylene blue is contraindicated in glucose-6-phosphate dehydrogenase (G6PD) positive cases. Hence it is of utmost importance to check for G6PD before embarking on treatment with methylene blue. Minucci et al. ${ }^{8}$ in their review article have explained in great detail about the principal recommendations with do's and don'ts while doing a G6PD assay.

To conclude, we recommend the following facts to be kept in mind while considering methemoglobinemia as one of the differentials: (1) Topical dapsone can also cause methemoglobinemia; (2) Bedside tests: Saturation gap, cooking and cooling method, filter paper test, and methemoglobin color chart test are easily available tests for priority diagnosis and timely treatment; (3) Methylene blue is the treatment of choice but G6PD test needs to be done before starting any patient on therapy. However, due to the ongoing hemolysis, the G6PD test could also be falsely negative making interpretation difficult; (4) Ascorbic acid is a cost effective alternative in cases where methylene blue is not available.

\section{CONFLICT OF INTEREST}

No potential conflict of interest relevant to this article was reported.

\section{REFERENCES}

1. Kang C, Kim DH, Kim T, et al. Therapeutic effect of ascorbic acid on dapsone-induced methemoglobinemia in rats. Clin Exp Emerg Med 2018;5:192-8.

2. Dhibar DP, Sahu KK, Jain S, Kumari S, Varma SC. Methemo- globinemia in a case of paint thinner intoxication, treated successfully with vitamin C. J Emerg Med 2018;54:221-4.

3. Dhibar DP, Sahu KK, Varma SC. Congenital methemoglobinemia: it is time for national level registry system. J Pediatr Hematol Oncol 2017;39:629.

4. Sahu KK, Dhibar DP, Gautam A, Kumar Y, Varma SC. Role of ascorbic acid in the treatment of methemoglobinemia. Turk $J$ Emerg Med 2016;16:119-20.

5. Deo P, Sahu KK, Dhibar DP, Varma SC. Naphthalene ball poisoning: a rare cause of acquired methaemoglobinaemia. BMJ Case Rep 2016;2016:bcr2016215102.

6. Senthilkumaran S, Senthilraj MP, Jena NN, Thirumalaikolundusubramanian P. Methaemoglobinaemia: recognition and realisation at bedside. Indian J Anaesth 2018;62:475-6.

7. Swartzentruber GS, Yanta JH, Pizon AF. Methemoglobinemia as a complication of topical dapsone. N Engl J Med 2015;372: 491-2.

8. Minucci A, Giardina B, Zuppi C, Capoluongo E. Glucose-6-phosphate dehydrogenase laboratory assay: how, when, and why? IUBMB Life 2009;61:27-34.

9. Reeves DJ, Saum LM, Birhiray R. I.V. ascorbic acid for treatment of apparent rasburicase-induced methemoglobinemia in a patient with acute kidney injury and assumed glucose6-phosphate dehydrogenase deficiency. Am J Health Syst Pharm 2016;73:e238-42.

10. Shihana F, Dawson AH, Buckley NA. A bedside test for methemoglobinemia, Sri Lanka. Bull World Health Organ 2016;94: 622-5.

11. Watton C, Smith K, Carter E. Methemoglobinemia as a complication of topical dapsone. N Engl J Med 2015;372:492. 